\title{
Delayed Auditory Tone Perception in Multiple Sclerosis
}

\author{
Douglas B. Quine, David Regan and Thomas J. Murray
}

SUMMARY: Delays of auditory perception at three frequencies were measured in 30 multiple sclerosis patients using a pscyhophysical technique. Nineteen patients had abnormal delays at one or more tone frequencies, though 15 had normal audiograms at those frequencies. In addition, auditory acuity for left-right asynchrony was abnormally poor in 13 patients, 9 of whom had normal audiograms. Such delays of auditory perception within a restricted frequency band may provide a partial explanation for degraded speech comprehension in some multiple sclerosis patients.

RÉSUMÉ: Chez 30 patients souffrant de sclérose en plaques nous avons mesuré la perception auditive à trois fréquences en employant une technique psychophysique. Dix-neuf patients avaient des réponses retardées pour une ou l'autre des fréquences tonales, même si 15 de ces patients avaient des audiogrammes normaux à ces fréquences. Chez 13 patients il y avait aussi une anomalie de l'asynchronie droite-gauche; 9 de ces patients avaient des audiogrammes normaux. De tels retards dans la perception auditive pour certaines fréquences restreintes pourraient expliquer partiellement la compréhension diminuée de la parole notée chez certains patients atteints de sclérose en plaques.

Can. J. Neurol. Sci. 1983; 10:183-186

The rationale for this study is based on the finding that, in some multiple sclerosis (MS) patients, visual perception is markedly delayed in one region of the visual field though perception is delayed much less or not at all in nearby regions only a few degrees away (Heron, Regan, and Milner, 1974; Regan, Milner, and Heron, 1976). Among possible explanations for such delays of visual perception, the most likely is demyelination of central nervous system (CNS) axonal fibres (Koles and Rasminsky, 1972; McDonald, 1974).

Authors who compare the visual and the auditory pathways commonly point out the analogy between the frequency of an auditory tone and location in the visual field or spatial frequency of a visual stimulus (Julesz, 1980). In particular, since position in the visual field has a topological representation in the optic radiations on visual cortex, it is easy to imagine how a local plaque of demyelination might slow or disrupt signal transmission from only a local region of the visual field.

We surmised that, in analogous manner, a local plaque of demyelination and/or neural damage in the auditory pathway might slow transmission of auditory signals originating in a local region of the basilar membrane. We were already aware that MS could produce a general slowing of auditory signals, since it has been reported that evoked potentials originating in auditory brainstem were delayed in some MS patients (Robinson and Rudge, 1975).

The present study was undertaken to determine whether MS patients experience delayed auditory perception and, if so, whether such delays can be restricted to a limited range of tone frequencies.

\section{METHODS}

\section{Psychophysical procedure}

The principle of our psychophysical procedure was to adjust the moment of onset of a tone in one ear relative to the moment of onset of a second tone in the other ear until the subject judged the two tones to switch on simultaneously. We used the following five different tone combinations:

Left $\operatorname{Ear}(\mathbf{H z})$
1000
1000
1000
500
2000

Right Ear (Hz)
500
1000
2000
1000
1000

In this way, we measured the interaural delay of one ear relative to a fixed reference tone of $1000 \mathrm{~Hz}$ in the other ear for each of three test frequencies in the test ear.

In a substantial preliminary study on 18 controls (132 tests) and 3 patients ( 8 tests), we used a staircase technique of moderately high psychophysical "efficiency" (Green and Swets, 1966; Levitt, 1971; Swets, 1973, Wetherill and Levitt, 1965). Stimulus delivery and data analysis were controlled by computer, and two staircases were interleaved in order to minimize the possibility that subjects might deduce the design of the staircase. Since both naive and experienced subjects found this task too difficult to obtain reliable results, we turned to a different psychophysical method.

From the Departments of Psychology, Biophysics, Physiology, Otolaryngology and Medicine, Dalhousie University, Halifax, Nova Scotia.

Presented in part to the Acoustical Society of America, Ottawa, May 1981.

Received October 18, 1982. Accepted for publication March 21, 1983.

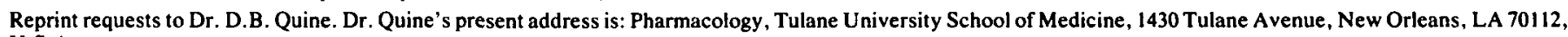
U.S.A. 
The data reported below were obtained using the method of ascending and descending limits. The duration of the stimulus tone was $1250 \mathrm{msec}$.

Tone onset was linear over $10 \mathrm{msec}$ and tone intensity was 50 dB SL. In the first run the right ear's tone started between 200 and $250 \mathrm{msec}$ before the left ear's. Both tones switched off together. The subject pressed one of two buttons, depending on whether he judged that the left ear's tone started before the right ear's or vice versa. Then the two tones were presented again with stimulus onset asynchrony (SOA) reduced by 30 msec. The process was repeated, reducing asynchrony in steps of $30 \mathrm{msec}$ until the subject judged the tone to start in the left ear twice in succession. A second run was then carried out with the

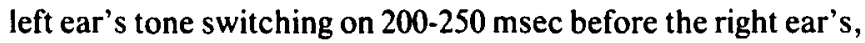
and SOA being again reduced in 30 -msec steps. The starting point was randomized at SOA between 200 and $250 \mathrm{msec}$. Four runs were carried out for each of the five different tone combinations, except for $1000 \mathrm{~Hz}$ versus $1000 \mathrm{~Hz}$ which was run eight times - four runs at the start and four at the end of the session. This $1000 \mathrm{~Hz} / 1000 \mathrm{~Hz}$ combination was used to assess reproducibility. Every session started with several practice runs.

\section{Apparatus}

All psychophysical sessions were controlled by a microcomputer (Commodore PET, 32K). Stimulus tones were generated by circuits of our own construction in which outputs were attenuated (Hewlett-Packard model 350D) and amplified (Citation 12 DeLuxe) before driving electrostatic earphones (Stax model SRX Mk 3). Auditory calibration was carried out by coupling the earphones to a Brüel and Kjaer model 2215 Sound Level Meter via an artificial ear (Bruël and Kjaer model 4152). Subjects sat in a soundproof chamber (Industrial Acoustics model 403-A). Audiograms were measured for each patient and control subject by means of a Grason-Stdler model 1704 audiometer. We regarded an audiogram as abnormal when the hearing loss exceeded $20 \mathrm{~dB}$ at any of the test frequencies $(500,1000$ or 2000 $\mathrm{Hz}$ ).

\section{Patients and control subjects}

Patients were diagnosed according to the criteria set out by Schumacher et al. (1965) and classified into "clinically definite", "probable", and "possible" groups (Rose et al., 1976). In addition, each patient was rated on the 10-point disability scale of Kurtzke (1965). A total of 30 patients with multiple sclerosis were tested, comprising 7 males and 23 females with ages ranging from 19 to 66 years. Clinical data are summarized in Table I. We did not require that the patients should have prior evidence of auditory involvement to be included in this study.

Eleven naive subjects were tested, comprising 4 males and 7 females, ranging in age from 18 to 60 years.

\section{Results}

\section{Interaural delay}

Interaural delays were measured for 30 patients and 11 control subjects. Interaural delays in control subjects ranged from $.95 \mathrm{msec}$ to $+83 \mathrm{msec}$ with a mean of $18 \mathrm{msec}$ and SD of 14 msec (Figure 1A). (Negative values correspond to left ear lead- ing while positive values correspond to right ear leading.) For patients, interaural delays ranged from $-167 \mathrm{msec}$ to $+126 \mathrm{msec}$ with a mean of $27 \mathrm{msec}$ and SD of $27 \mathrm{msec}$ (Figure 1B). MS patients showed significantly longer interaural delays than did the control subjects [Mann-Whitney U test for large samples: $z$ $=3.13, \mathrm{p}=0.0009$ (Siegel, 1956)]. In the five experimental conditions (tone combinations), only 4 of 66 control tests (6\%) exceeded the 2.5 standard deviation $(<-17 \mathrm{msec}$ or $>+53$ $\mathrm{msec}$ ), while 45 out of 180 tests ( $25 \%$ ) on patients exceeded this criterion.

Of the 30 patients tested, 19 showed abnormal interaural delay at one or more tone frequencies. One, two, or all three test frequencies could show an abnormal delay. Ten patients had a delay in both ears. In 15 of these 19 patients, the frequencyselective delay was associated with a clinically normal audiogram (i.e. less than $20 \mathrm{~dB}$ loss) in the affected part of the auditory spectrum. To emphasize this point further, we note that in the parts of the auditory spectrum where interaural delay was abnormal, 13 patients had pure tone thresholds for the left and right ears that differed by only $5 \mathrm{~dB}$ or less, 4 patients had a 10 -dB difference, 1 differed by $15 \mathrm{~dB}$, and 1 differed by $20 \mathrm{~dB}$.

Although test-to-test repeatability was poorer than we could have wished in quantitative terms, patients with abnormally large delays generally gave delays outside normal limits on the second and subsequent retests, while patients whose delays were inside control limits generally remained within control limits on the second and subsequent retests.

Table I: Clinical data and auditory test results.

\begin{tabular}{|c|c|c|c|c|c|c|c|c|}
\hline Patient & Sex & $\begin{array}{l}\text { Age } \\
1980\end{array}$ & Diagnosis & Kurtzke & $\begin{array}{c}\text { Date of } \\
\text { Onset }\end{array}$ & $\begin{array}{l}\text { Audio- } \\
\text { gram }\end{array}$ & $\begin{array}{c}\text { Auditory } \\
\text { Delay }\end{array}$ & $\begin{array}{c}\text { Inter- } \\
\text { aural } \\
\text { Acuity }\end{array}$ \\
\hline 1 & $\mathbf{M}$ & 51 & Definite & 2 & 1974 & $\mathbf{N}$ & $\mathbf{N}$ & $\mathbf{N}$ \\
\hline 2 & $\mathbf{F}$ & 33 & Definite & 3 & 1978 & $\mathbf{N}$ & A & A \\
\hline 3 & $\mathbf{F}$ & 30 & Definite & 1 & 1974 & $\mathbf{N}$ & A & $\mathbf{N}$ \\
\hline 4 & $\mathrm{~F}$ & 28 & Possible & 0 & 1978 & $\mathbf{N}$ & A & $\mathbf{N}$ \\
\hline 5 & $F$ & 33 & Definite & 2 & 1975 & $\mathbf{N}$ & $\mathbf{N}$ & $\mathbf{N}$ \\
\hline 6 & $\mathbf{M}$ & 35 & Probable & 1 & 1975 & $\mathbf{N}$ & $\mathbf{N}$ & $\mathbf{N}$ \\
\hline 7 & $\mathbf{F}$ & 38 & Definite & 3 & 1973 & A & $\mathbf{N}$ & A \\
\hline 8 & $\mathbf{F}$ & 32 & Definite & 0 & 1972 & $\mathbf{N}$ & A & $A$ \\
\hline 9 & $\mathrm{M}$ & 55 & Definite & 6 & 1966 & $A$ & A & $\mathbf{N}$ \\
\hline 10 & $\mathbf{F}$ & 23 & Definite & 6 & 1977 & $\mathbf{N}$ & A & A \\
\hline 11 & $\mathbf{F}$ & 30 & Definite & 3 & 1971 & A & A & A \\
\hline 12 & $\mathbf{M}$ & 56 & Definite & 7 & 1942 & $\mathbf{N}$ & A & $\mathrm{N}$ \\
\hline 13 & $\mathbf{M}$ & 48 & Possible & 1 & 1975 & $\mathbf{N}$ & $\mathbf{N}$ & $\mathbf{N}$ \\
\hline 14 & F & 53 & Definite & 6 & 1971 & A & A & A \\
\hline 15 & $\mathrm{~F}$ & 25 & Definite & 1 & 1974 & $\mathbf{N}$ & $\mathrm{N}$ & $\mathbf{N}$ \\
\hline 16 & $\mathbf{F}$ & 19 & Probable & 1 & 1974 & $\mathbf{N}$ & $\mathbf{N}$ & $\mathbf{A}$ \\
\hline 17 & $\mathbf{F}$ & 48 & Definite & 6 & 1966 & $\mathbf{N}$ & A & A \\
\hline 18 & $\mathbf{F}$ & 22 & Probable & 1 & 1975 & $\mathbf{N}$ & $\mathbf{N}$ & $\mathbf{N}$ \\
\hline 19 & $\mathbf{F}$ & 33 & Definite & 1 & 1975 & $\mathbf{N}$ & A & A \\
\hline 20 & $\mathbf{F}$ & 37 & Definite & 1 & 1976 & $\mathbf{N}$ & $\mathbf{A}$ & $\mathbf{N}$ \\
\hline 21 & $\mathbf{F}$ & 47 & Definite & i & 1957 & $\mathbf{N}$ & A & $A$ \\
\hline 22 & $\mathbf{F}$ & 54 & Definite & 6 & 1958 & $\mathbf{N}$ & $\mathbf{N}$ & $\mathbf{N}$ \\
\hline 23 & $\mathbf{M}$ & 44 & Definite & 2 & 1972 & $\mathbf{N}$ & A & $\mathbf{N}$ \\
\hline 24 & $\mathrm{~F}$ & 30 & Definite & 6 & 1973 & $\mathbf{N}$ & A & A \\
\hline 25 & $\mathrm{~F}$ & 34 & Definite & 6 & 1970 & $\mathbf{N}$ & A & $\mathbf{N}$ \\
\hline 26 & $\mathbf{F}$ & 26 & Definite & 0 & 1976 & $\mathrm{~N}$ & $\mathbf{N}$ & $\mathbf{N}$ \\
\hline 27 & $\mathbf{M}$ & 65 & Definite & 7 & 1945 & $\mathbf{N}$ & A & A \\
\hline 28 & $\mathbf{F}$ & 45 & Definite & 1 & 1974 & $\mathbf{N}$ & A & $\mathbf{N}$ \\
\hline 29 & $\mathbf{F}$ & 25 & Probable & $i$ & 1971 & $\mathbf{N}$ & $\mathbf{N}$ & $\mathbf{N}$ \\
\hline 30 & $\mathbf{F}$ & 66 & Definite & 6 & 1950 & $\mathbf{A}$ & $\mathbf{A}$ & A \\
\hline
\end{tabular}

Key: Audiogram normal $(\mathrm{N})$ - less than $20 \mathrm{~dB}$ loss in the range 500$2000 \mathrm{~Hz}$. Audiogram abnormal (A) - more than $20 \mathrm{~dB}$ loss in the range $500-2000 \mathrm{~Hz}$. Auditory delay normal $(\mathrm{N})$ - between $-17 \mathrm{msec}$ and +53 msec; abnormal (A) - below $-17 \mathrm{msec}$ or more than $+53 \mathrm{msec}$. Interaural acuity normal $(\mathrm{N})$ - less than $174 \mathrm{msec}$; abnormal (A) - more than 175 msec. 


\section{CONTROL DELAY}

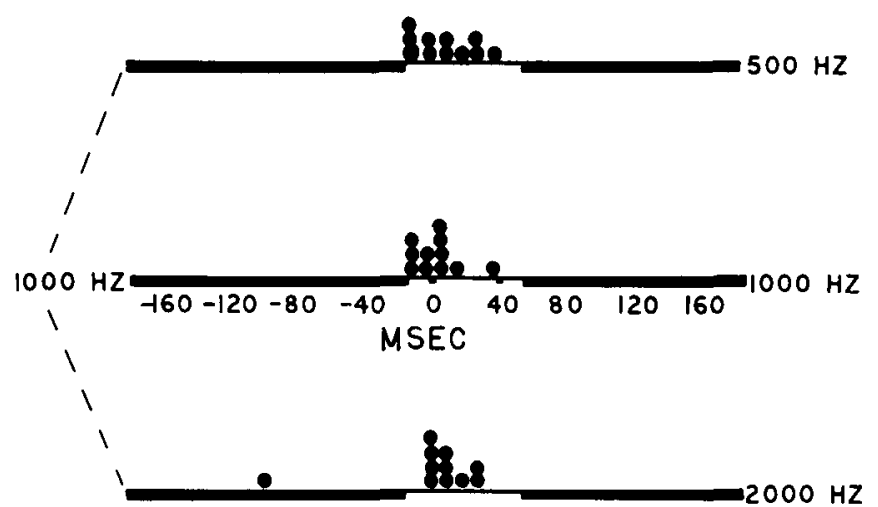

MULTIPLE SCLEROSIS DELAY

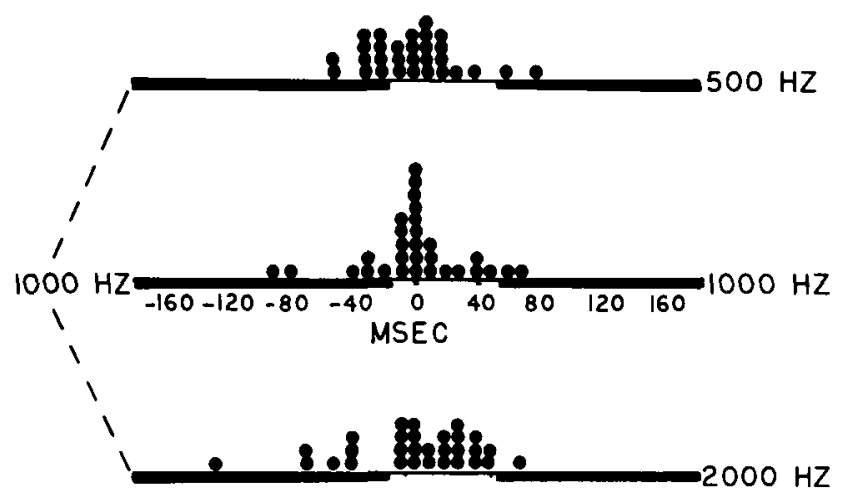

Figure I - A - Interaural delays of auditory perception for 11 control ears. The horizontal black bars mark delays more than 2.5 standard deviation from the control mean. B - Interaural delays for multiple sclerosis patients showing some patients with abnormally large delays at particular tone frequencies. These measurements are for a $1000-\mathrm{Hz}$ reference tone in the left ear and for $500 \mathrm{~Hz}, 1000 \mathrm{~Hz}$ and $2000 \mathrm{~Hz}$ tones in the right ear, all tones being of duration $1250 \mathrm{msec}$. Similar measurements with the $1000-\mathrm{Hz}$ reference in the right ear are not shown.

\section{Acuity for binaural synchrony}

For each tone combination, we computed the difference between the mean interaural delay for the two runs in which the stimulus began in the left ear and the mean interaural delay for the two runs in which the stimulus began in the right ear. We took this difference as a measure of acuity for binaural asynchrony. For control subjects the range of values was $0 \mathrm{msec}$ to $195 \mathrm{msec}$ with a mean of $62 \mathrm{msec}$ and SD of $45 \mathrm{msec}$ (Fig. 2A), while for MS patients the values ranged from $0 \mathrm{msec}$ to $427 \mathrm{msec}$ with a mean of $99 \mathrm{msec}$ and SD of $72 \mathrm{msec}$ (Fig. 2B). MS patients showed significantly greater ranges than the control subjects did [Mann-Whitney U test for large samples: $z=3.84, p<0.00007$ (Siegel, 1956)].

The 2.5 standard deviation criterion ( $175 \mathrm{msec}$ ) was exceeded in only 1 of the 66 control tests $(1.5 \%)$, while it was exceeded in 25 of 180 tests on patients (14\%).

Of 30 patients tested, 13 had abnormally low acuity at one or more test frequencies. Of these 13 patients, 9 had normal audiograms in the relevant parts of the auditory spectrum. To emphasize this point further we note that, in the parts of the auditory

\section{CONTROL SPREAD}

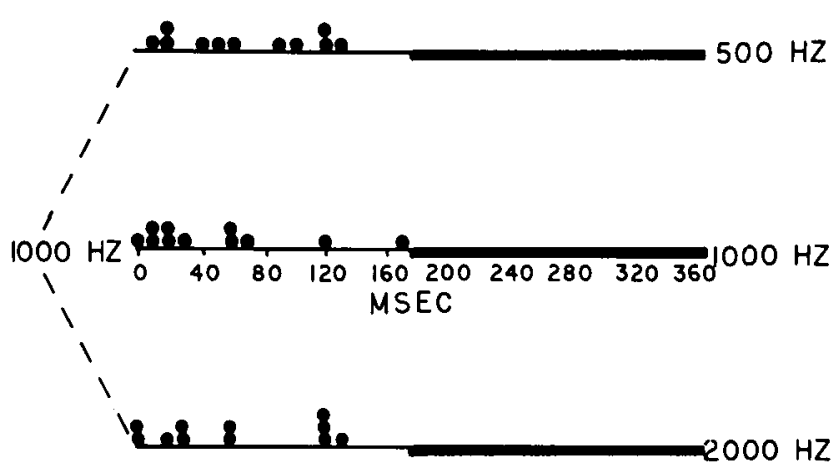

MULTIPLE SCLEROSIS SPREAD

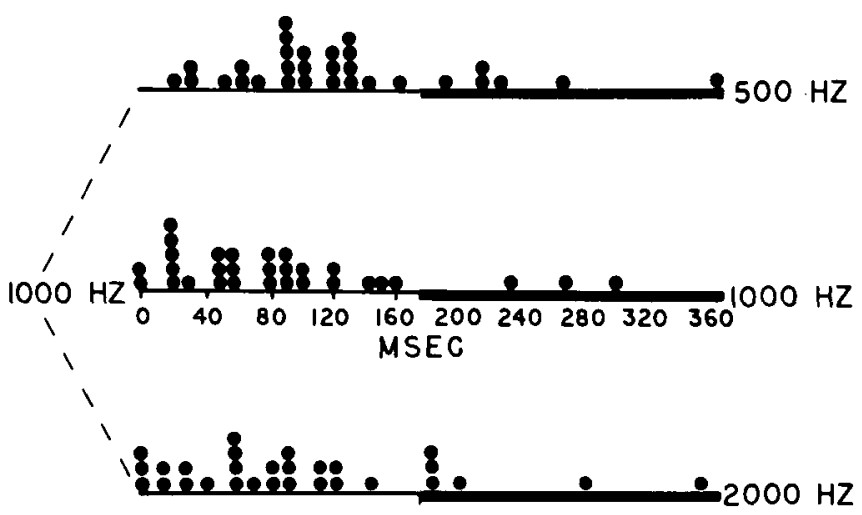

Figure 2-A-Acuity for binaural asynchrony in 11 control ears. Each point shows the difference in interaural delay for which a stimulus was reported "left ear first" and for which it was reported "right ear first". The horizontal black bars mark values more than 2.5 standard deviations from the control mean. B - Similar data for multiple sclerosis patients showing some patients with abnormally poor acuity for binarual asynchrony at particular tone frequencies. As for Figure 1, all measurements shown are for a $1000-\mathrm{Hz}$ reference tone in the left ear.

spectrum where acuity was abnormal, 8 patients had pure tone thresholds for the left and right ears that differed by $5 \mathrm{~dB}$ or less, 4 patients had a $10 \mathrm{~dB}$ difference, and 1 differed by $15 \mathrm{~dB}$ (Table I).

\section{Discussion}

\section{Delays of auditory perception that varied with tone frequency}

Our chief conclusion is that auditory perception can be delayed over a restricted frequency band, even though perception is not delayed for tones of other frequencies. In particular, significant variations of delay can exist between tones as close as 500 and $1000 \mathrm{~Hz}$, or 1000 and $2000 \mathrm{~Hz}$. These frequency-specific delays can occur in the absence of any abnormality in pure tone intensity thresholds.

The frequency-dependent delays might be explained in terms of local plaques of demyelination and/or neural damage if we can assume that such pathology occurs at a neuroanatomical site where signals evoked by different frequency tones are spatially separated. 


\section{Acuity for binaural asynchrony}

The range of interaural delays over which the tones were judged to be simultaneous was abnormally broad in a substantial number of patients (13/30). We take this range as a measure of acuity for binaural asynchrony.

In studies of temporal order discrimination, Jerger et al. (1969) reported control subjects to have an interaural resolution of 20-40 msec in a paradigm similar to ours. Our slightly poorer thresholds ( $62 \mathrm{msec}$ in controls) can probably be attributed to less experienced subjects. Like Jerger et al. (1969) we used stimuli of random phase. This enabled us to compare temporal resolution of different frequencies.

Hasler and Levine (1980), found interaural time discrimination was degraded in 13 of 29 patients, though their technique differed in that the same (noise) waveform was presented to each ear. Their phase-locked stimuli enabled subjects to use phase cues which our stimuli did not. (Phase cues permit lateralization of stimuli with only a fraction of a millisecond discrepancy.)

\section{Relation to SBMPL test results}

Our psychophysical findings may relate to Noffsinger et al.'s (1972) report that $12 / 60$ patients with MS gave abnormal results on the simultaneous binaural median plane location (SBMPL) test. In this test the same pure tone was presented to left and right ears, and the intensity of the stimulus to one ear was varied until the patient perceived the sound source to be located at the midline. Of 60 patients tests, Noffsinger et al. reported that 12 either could not experience a midline image or did so only when different intensities were presented to the two ears. They underlined their finding that, of these 12 , only 5 had difficulties in performing the task, contrasting this with the well-known observation that patients with brainstem lesions often find the SBMPL task difficult since they do not perceive a single fused image or cannot shift the image.

\section{Frequency-dependent delays and speech comprehension}

We find that auditory perception can be delayed even when the audiogram is normal. In other words, the intensity threshold for pure tones may be unaffected even though perception is delayed. Nevertheless, it is possible that delayed auditory signals might degrade everyday hearing, especially when delays are different for different pure tones. In particular, it seems possible that speech comprehension would be affected by distorting the relative timing of auditory signals originating in different parts of the basilar membrane. Thus, frequencydependent delays might degrade speech comprehension in MS patients, even though the disorder might not be detected by pure tone audiometry. Frequency-dependent delays might be a factor in the unexplained poor performance on speech sound recognition tests of some patients with MS who have normal audiograms (Citron et al., 1963; Noffsinger et al., 1972; Sidtis et al., 1979).

\section{ACKNOWLEDGMENTS}

We thank patients and control subjects for their patience and good humour. We thank Dr. K.I. Beverley for his advice on electronics. This research was supported by the Multiple Sclerosis Society of Canada, and by the NSERC of Canada (Grant G-0052 to DR).

\section{REFERENCES}

Citron, L., Dix, M.R., Hallpike, C.S. \& Hood, J.D. (1963). A recent clinopathological study of cochlear nerve degeneration resulting from tumour pressure and disseminated sclerosis. Acta Otolaryngology 56:330-337.

Green, D.M. \& Swets, J.A. (1966) Signal detection theory and psychophysics. Wiley, New York.

Hausler, R. \& Levine, R.A. (1980), Brain stem auditory evoked potentials are related to interaural time discrimination in patients with multiple sclerosis. Brain Res 191:589-594.

Heron, J.R., Regan, D. \& Milner, B.A. (1974) Delay in visual perception in unilateral optic atrophy after retrobulbar neuritis. Brain 97:69-78.

Jerger, J., Weikers, N.J., Sharbrough, F.W. III \& Jerger, S. (1969) Bilateral lesions of the temporal lobe: A case study. Acta Otolaryngologia Suppl. 258:1-51.

Julesz, B. (1980) Spatial frequency channels in one-, two- and threedimensional vision: variations on an auditory theme by Békésy. In Visual coding and adaptability (ed. C.S. Harris). Erlbaum: Hillsdale, N.J.

Koles, Z.J. \& Rasminsky, M. (1972) A computer simulation of conduction in demyelinated nerve fibres. J. Physiol. 227:351-364.

Kurtzke, J.F. (1965) Further notes on disability evaluation in multiple sclerosis, with scale modifications. Neurology 15:654-661.

Levitt, H. (1971) Transformed up-down methods in psychoacoustics. J. Acoust. Soc. Amer. 49:467-477.

McDonald, W.I. (1974) Pathophysiology in multiple sclerosis. Brain 97:179-196.

Noffsinger, D., Olsen, W.O., Carhart, R., Hart, C.W. \& Sahgal, V. (1972) Auditory and vestibular aberrations in multiple sclerosis. Acta Oto-laryngology Suppl. 303:1-63.

Regan, D. , Milner, B.A.\& Heron, J.R. (1976) Delayed visual perception and delayed visual evoked potentials in the spinal form of multiple sclerosis and in retrobulbar neuritis. Brain 99:43-66.

Robinson, K. \& Rudge, P. (1975) Auditory evoked responses in multiple sclerosis. Lancet 1:1164-1166.

Rose, A.S., Ellison, G.W., Myers, L.W. \& Tourtellotte, W.W. (1976) Criteria for the clinical diagnosis of multiple sclerosis. Nerology 26 no. 6 pt. 2:20-22.

Schumacher, G.A., Beebe, G., Kibler, R.F., Kurland, L.T., Kurtzke, J.F., McDowell, F., Nagler, B., Sibley, W.A., Tourtellotte, W.W. \& Willmon, T.L. (1965) Problems of experimental trials of therapy in multiple sclerosis: Report by the panel on the evaluation of experimental trials of therapy in multiple sclerosis. Ann. N.Y Acad. Sci. 122:552-568.

Sidtis, J.J., Volpe, B.T. \& Gazzaniga, M.S. (1979) Impaired auditory pattern recognition in multiple sclerosis. Neurology 29:597 (Abstract pp. 98).

Siegel, S. (1956) Nonparametric statistics for the behavioral sciences. McGraw Hill, Nwe York.

Swets, J.A. (1973) The relative operating characteristic in psychology. Science 182:990-1000.

Wetherill, G.B. \& Levitt, H. (1965) Sequential estimation of points on a psychometric function. Br. J. Math. Stat. Psychol. 18:1-10. 